*aMIS View/Print Document Cover Sheet

This document was retrieved from the Boeing ISEARCH System.

Accession \#: D196050225

Document \#: SD-TD-RPT-015

Title/Desc:

DETECTION \& QUANTITATIVE ANALYSIS OF CHEMICAL SPECIES IN HANFORD TANK MATERIALS USING RAMAN SPECTROSCOPY TECHNOLOGY FY1994 FLSU RAMAN SPECTROSCOPY RPT 


\begin{tabular}{l|l|}
$\begin{array}{l}\text { 2. To: (Receiving Organization) } \\
\text { Distribution }\end{array}$ & $\begin{array}{l}\text { 3. From: (Originating Organization) } \\
\text { Sensor/Analytical Technical } \\
\text { Projects }\end{array}$ \\
\hline $\begin{array}{l}\text { 5. Proj./Prog./Dept./Div.: } \\
\text { OM582 / H2CAA }\end{array}$ & $\begin{array}{l}\text { 6. Cog. Engr.: } \\
\text { F. R. Reich }\end{array}$ \\
\hline $\begin{array}{l}\text { 8. Originator Renarks: } \\
\text { FY94 Raman Spectroscopy Technology work on Tank Materials by } \\
\text { Florida State University. }\end{array}$
\end{tabular}

11. Receiver Remarks:
4. Related EDT No.:

$N / A$

7. Purchase Order No.:

N/A

9. Equip./Component No.:

$N / A$

10. System/Bldg./Facility:

$N / A$

12. Major Assm. Dwg. No.: $N / A$

13. Permit/Permit Application No.: $N / A$

14. Required Response Date:

$09 / 22 / 95$

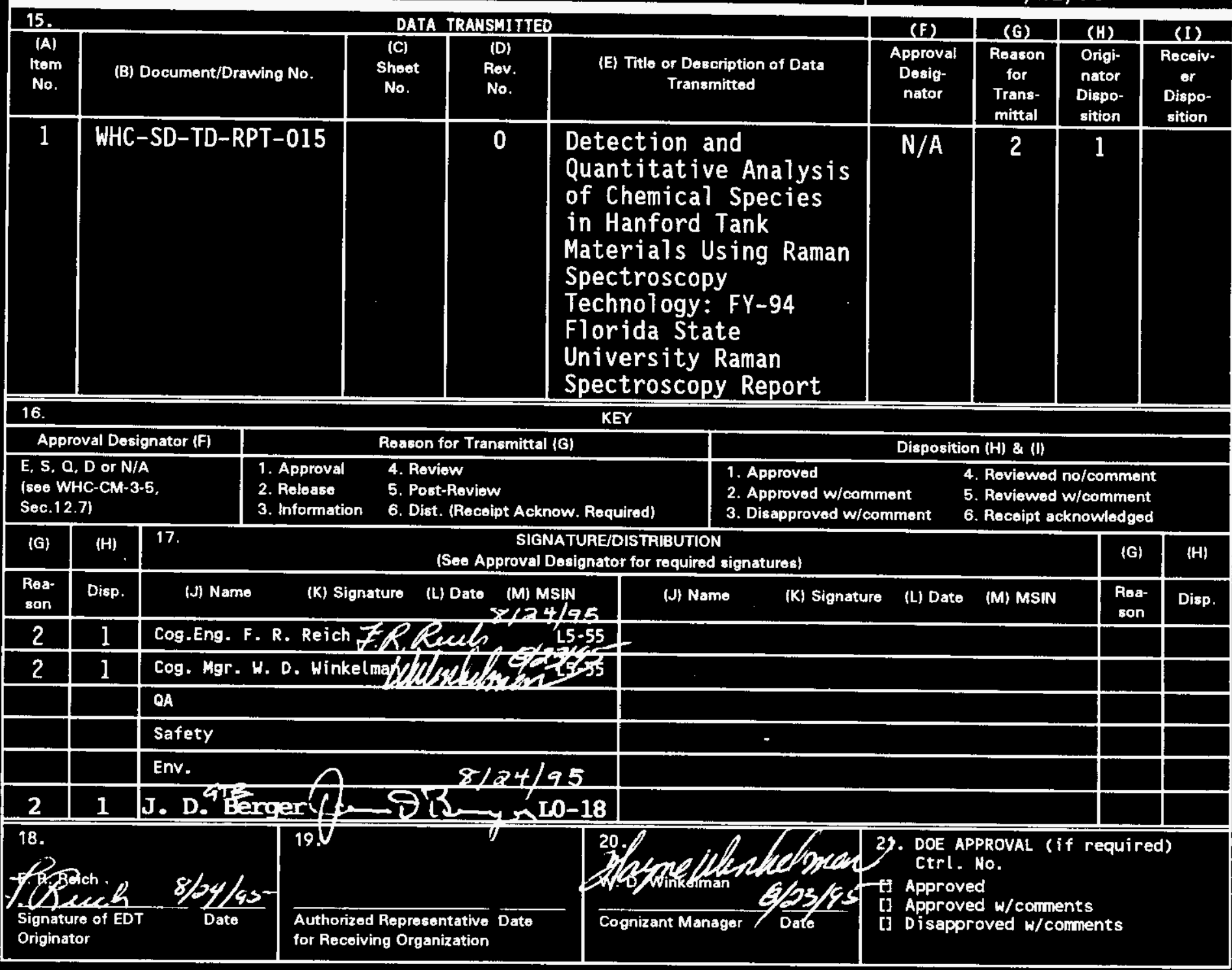


THIS PAGE INTENTIONALLY LEFT BLANK 


\section{RELEASE AUTHORIZATION}

\begin{tabular}{|ll|}
\hline Document Number: & WHC-SD-TD-RPT-015, Rev. O \\
\hline Document Title: & $\begin{array}{l}\text { Detection and Quantitative Analys is of Chemical } \\
\text { Species in Hanford Tank Materials Using Raman } \\
\text { Spectroscopy Technology: FY-94 Flordia State } \\
\text { University Raman Spectroscopy Report }\end{array}$ \\
\hline Release Date: & $9 / 7 / 95$ \\
\hline
\end{tabular}

This document was reviewed following the
procedures described in WHC-CM-3-4 and is:

APPROVED FOR PUBLIC RELEASE

WHC Information Release Administration Specialist:

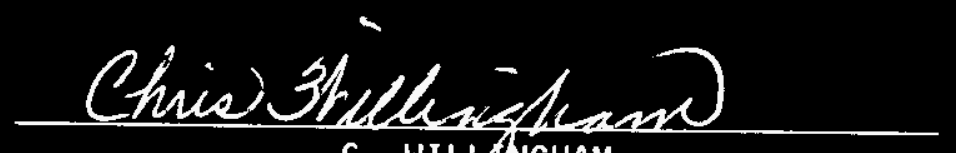

$9 / 7 / 95$

$$
\text { c. WILLWGHAM }
$$

TRADEMARK DISCLAIMER. Reference here in to any specific commercial product, process, or service by trade name, trademark, manufacturer, or otherwise, does not necessarily const itute or imply its endorsement, recommendation, or favoring by the United States Government or any agency thereof or its contractors or subcontractors.

This report has been reproduced from the best available copy. Available in paper copy. Printed in the United States of America. To obtain copies of this report, contact:

Westinghouse Hanford Company - Document Control Services

P.0. Box 1970, Mailstop H6-08, Richland, WA 99352

Telephone: (509) 372-2420; Fax: (509) 376-4989

Windows is a trademark of Microsoft Corporation. 
THIS PAGE INTENTIONALLY LEFT BLANK 


\begin{tabular}{|l|l|c|}
\hline 2. Titte & 3. Number & 4. Rev No. \\
Detection and Quantitative Analysis of Chemical \\
Species in Hanford Tank Materials Us ing Raman \\
$\begin{array}{l}\text { Spectroscopy Technology: FY-94 Florida State } \\
\text { University Raman Spectroscopy Report }\end{array}$ & WHC-SD-TD-RPT-015 \\
\hline $\begin{array}{l}\text { 5. Key Words } \\
\text { Raman Spectroscopy, Raman Measurements, } \\
\text { Morphology, Species Identification, Species } \\
\text { Concentration }\end{array}$ & $\begin{array}{l}\text { 6. Author } \\
\end{array}$ & Nome: T. J. Vickers/C.K.Mann \\
\hline
\end{tabular}

7. Abstract

This report provides a summary of work completed in FY-94 by FSU to develop and investigate the feasibility of using Raman spectroscopy with Hanford tank waste materials. Raman performance impacts from sample morphology, including the effects of absorption, particle size, density, color and refractive index, are discussed. An algorithm for relative species concentration measurement from Raman data is presented. An algorithm for applying Raman to tank waste core screening is presented and discussed. A library of absorption and Raman spectra are presented that support this work. 
THIS PAGE INTENTIONALLY LEFT BLANK 


\title{
Report
}

on

Detection and Quantitative Analysis of Chemical Species in Hanford Tank Materials Using Raman Spectroscopy Technology: FY-94

\section{Reporting Period : January 1, 1994 - March 31, 1995}

\author{
by
}

Florida State University

Prepared for Westinghouse Hanford Company under Contract No. MJG-SVV-562928

by

Florida State University, Tallahassee, FL 32306-3006

This work was funded by the U.S. Department of Energy, Ofice of Environmental Management, Office of Technology Development (EM-50) 
THIS PAGE INTENTIONALLY LEFT BLANK 


\section{REPORT}

$1 / 1 / 94-3 / 31 / 95$

Continuation of PR\#562928

\section{Thomas J. Vickers and Charles K. Mann}

Department of Chemistry, Florida State University, Tallahassee, FL 32306-3006

904-644-1846 (TJV), 904-644-3747 (CKM), FAX: 904-644-8275

New technologies are needed to support the safe and environmentally responsible operation and surveillance of Hanford's High Level Waste Storage Tanks. The concentrations of ferri- and ferrocyanides, nitrates, nitrites, and various other inorganic and organic species in the tank wastes are of critical concern. Fiber-optic Raman spectroscopy is clearly one of the most promising approaches to meet the needs of the tank waste program at Hanford. Florida State University (FSU) has developed expertise in the area of Raman spectroscopy that is relevant to the needs of the Hanford high level waste program over more than a dozen years. For the past three years FSU has worked closely with staff at Hanford to meet the special requirements of the Hanford program and transfer the appropriate technology from our laboratory to the Hanford setting. This report is intended to provide a concise summary of the effort since January 1, 1994. Efforts in this period were organized around five tasks: task 19--technical assistance, task 20--sample morphology effects, task 21--species identification, task 22--quantitative analysis algorithm, task 23--screening algorithm. In practice there is interaction and overlap among these tasks, but for purposes of this report each is separately addressed. 
THIS PAGE INIENTIONALLY LEFT BLANK 


\section{TASK 19: TECHNICAL ASSISTANCE}

\section{Introduction}

Raman spectroscopy, has until recently, been confined almost entirely to the research laboratory. Recent developments in optics, detectors, computers and fiber optics have made it practical to apply Raman spectroscopy in the routine analysis of complex samples. The major goal of this task was to transfer Raman spectroscopy expertise and experience to Hanford that is relevant to the needs of the Hanford's high level waste disposal problems.

\section{Activities}

No deliverables were specified for this task. As in the past, FSU has provided on-call assistance to the project managers at Hanford. The FSU project managers attended an annual workshop that reviewed progress on the Raman project and made plans for future work. Copies of the FSU presentations on waste simulant data, instrument developments, data archiving, and data analysis are included in the workshop report. 
THIS PAGE INTENTIONALLY

LEET BLANK 


\section{TASK 20: SAMPLE MORPHOLOGY EFFECTS ON RAMAN SPECTRA}

\section{Introduction}

Sample morphology includes the effect of sample properties such as particle size, matrix refractive index, moisture content, and absorption. These properties can affect the depth of radiation penetration and thereby the amount of material contributing to the Raman signal. Full utilization of the ability of Raman spectroscopy for qualitative and quantitative analysis requires understanding the effects of sample morphology on Raman spectra. Materials that mimic the range of sample morphologies encountered in tank wastes must be examined and their effects on Raman signal intensities investigated to develop strategies to mitigate these effects. Measurements at Hanford on real tank wastes are needed to guide the evolution of the laboratory studies here. The major goal of work in this task was to lay the basis for the study of sample morphology effects by carrying out measurements on samples in which the sample morphology was varied in a systematic fashion.

\section{Absorption}

In other aspects of this project Raman spectra have been measured/recorded for a number of compounds. ${ }^{1}$ In doing this, occasionally colored materials are encountered which are difficult to obtain Raman spectra from. Other investigators have described similar problems. ${ }^{2,3}$ This led to the examination of the role of visible and near-infrared absorption in Raman measurements. The effect of absorption in Raman measurement of solutions has previously been characterized. ${ }^{4}$ Addressing the effect of absorption in inorganic solids poses some additional difficulties. A mulling technique for transmission measurements of solid inorganic materials has recently been described. This technique might provide some insight on the source of difficulty in Raman measurements of certain colored materials. Table 20-1 lists materials which have been included in this study. An attempt was made to record the Raman spectra for the materials in Table 20-1 with both the $514.5 \mathrm{~nm}$ laser multichannel-Raman system and the $1064 \mathrm{~nm}$ laser FT-Raman system. (Delayed deliver of a diode laser system operating at $785 \mathrm{~nm}$ made it impossible to include results at this wavelength in the current study.) The results indicated that there was no clear correlation between absorption as recorded by the mulling technique and failure to record Raman spectra with either or both Raman systems. Figure 20-1 provides an example of the confounding results.

Figure 20-1A shows the absorption spectrum of copper phthalocyanine obtained by the mulling technique. The shaded regions cover the Stokes-Raman wavelength ranges for $514.5 \mathrm{~nm}$ and $1064 \mathrm{~nm}$ laser excitation. This spectrum indicates strong absorption by the material in the vicinity of the $514.5 \mathrm{~nm}$ laser and what appears to be relatively weak absorption in the vicinity of the $1064 \mathrm{~nm}$ laser. Despite this result, the Raman spectrum of 
copper phthalocyanine is readily obtained with the $514.5 \mathrm{~nm}$ system, as shown in Figs. 201B, and obtained only with great difficulty with the FT system.

The specific absorption and Raman spectra obtained for the materials listed in Table 20-1 are included in Appendix 20-1. The absorption spectra are displayed as absorbance $x$ 1000 versus pixel number. The abscissa can be converted to wavelength in $\mathrm{nm}$ by assuming an origin at $350 \mathrm{~nm}$ and an increment of $2 \mathrm{~nm}$ per pixel. The Raman spectra obtained with $514.5 \mathrm{~nm}$ excitation and CCD detection are displayed as Raman intensity in arbitrary units versus wavenumber shift. The FT-Raman spectra obtained with $1064 \mathrm{~nm}$ excitation are displayed as arbitrary intensity versus pixel number. The abscissa can be converted to wavenumber shift by assuming an origin at a wavenumber shift value of 116 $\mathrm{cm}^{-1}$ with an increment of $1.28 \mathrm{~cm}^{-1}$ per pixel.

As noted above, there is no clear correlation between the absorption spectra obtained by the mulling technique and success or failure in obtaining Raman spectra by the CCD or FT techniques at quite different laser wavelengths. Raman spectra were obtained with a CCD based Raman system for all the materials listed in Table 20-1 except ferric oxide. The Raman spectra for only eight of the compounds was obtained with a FourierTransform (FT) Raman system. For KMnQ the FT system gave a noticeably better spectrum. The wollastonite spectrum was somewhat better with the FT system.

Wollastonite exhibited notable "fluorescence" at both the 514.5 and 1064 nm wavelengths.

\section{Particle Size}

Sodium nitrate was ground and sieved to produce samples with different particle size distributions. Figure 20-2 shows the Raman spectra obtained for three of the size fractions. The intensity of the Raman spectrum varies with particle size, but line shapes and position are not affected for the range of particle sizes investigated in this study. Figure 20-3 shows a plot of least squares fit value for the sodium nitrate spectrum versus average particle diameter.

Reflectance spectra were measured for the same set of samples. As particle size decreased, the parameter corresponding to absorbance in reflectance measurements, $\log$ $(1 / R)$, decreased. This trend is consistent with the noted increase in Raman intensity as particle size decreased.

\section{Packing Density}

The effect of particle packing was examined by compressing sodium nitrate powder at different pressures in a pellet press. The results of one such study are shown in Fig. 20-4.

\section{Suspensions}

In this study we sought to examine the effect of suspended solids on the Raman signal of a liquid medium. The results of one such study are shown in Fig. 20-5. Various weights of insoluble solid were suspended in $1 \mathrm{M}$ sodium nitrate. The nitrate spectrum was measured for each sample. Figure 20-5 shows the nitrate least squares fit value versus weight of suspended solid for each of three solids. For the two white solids, calcium carbonate and titanium dioxide, the higher refractive index material had a larger 
attenuating effect on the intensity of the nitrate Raman spectrum. The strongest attenuating effect occurred with suspended silicon carbide, which has almost as high a refractive index as the titanium dioxide and is gray in color.

\section{Sfifect of Color and Refractive Index}

To further investigate the effects of color and refractive, a study on paints was also completed. The study above shows a comparison of absorbance and Raman results. The pain study provides a different view of the question of sample color and Raman sensitivity. This study of paints allowed further adjustment of some of the attributes of sample behavior.

The example, shown in Fig. 20-6, is polyurethane film. This is a two-pack product that is sold as an isocyanate component and a polyester component, both with various additives. Films are formed by mixing equal volumes of the two materials and spreading, by brush or spray. Drying occurs both by evaporation of the solvents and by reaction of the isocyanate with the active hydrogens of the polyester to form polyurethane, which will be in the form of a thin layer, owing to the mode of application. Used in this form, the product forms a tough transparent coating which displays the substrate. Mixed with pigments and other additives, it forms a paint film.

On the left side of Fig. 20-6, spectra of three forms of this product are shown. They were made under the same spectroscopic conditions. The top is the transparent version. Below that are the spectra of a yellow and white paint. The principal component of the white paint, aside from the binder, is rutile titanium dioxide. This is responsible for the three peaks around $500 \mathrm{~cm}^{-1}$. The spectrum of $\mathrm{TiO}_{2}$ is empty except for these three peaks. The yellow differs from the transparent version primarily in containing nickel titanate yellow. This is $\mathrm{TiO}_{2}$ which has been doped with a nickel salt to produce a brilliant yellow pigment. Doping does not cause the appearance of new peaks, compared with $\mathrm{TiO}_{2}$, but instead causes small shifts in the positions of the $\mathrm{TiO}_{2}$ peaks. Accordingly, the yellow films shows three $\mathrm{TiO}_{2}$ peaks which look like those of the white film but are actually in slightly different positions.

So far as color is concerned, one would expect that the intensity of the Raman features, as indicated by the $\mathbf{S} / \mathbf{N}$, would be greatest for the transparent film since the laser beam can penetrate it completely. It should be next best for the white film, since the pigment reflects all colors equally, and worst for the yellow film, since it absorbs green.

On the right side of Fig. 20-6, the sections of spectra that contain features from the binder are shown, scaled to make the $\mathrm{CH}$ regions the same size. There are small differences in the films, owing to differences in the additives that were used. However, it is apparent that they are mainly the same. The signal to noise ratio (S/N) for the transparent film is better than those of the other two, as expected. However, the S/N for the white paint is quite a bit poorer than for the other two.

One can see from the complete spectra on the left side why this is so. The white film contains considerably more $\mathrm{TiO}_{2}$ than the yellow. This is indicated by the relative sizes of the $\mathrm{CH}$ and $\mathrm{TiO}_{2}$ features in the two spectra. Even though the yellow is intensely colored, 
the effect of changing the amount of $\mathrm{TiO}_{2}$ with its large refractive index is more important than color in determining the sensitivity of the measurement.

Examination of paint films leads to the conclusion that sample color usually is not a major factor in determining Raman sensitivities. Dark blues and greens behave pretty much as the dark yellow in the example. Carbon black is an exception. It absorbs all visible wavelengths and does appreciably degrade the $\mathbf{S} / \mathrm{N}$ of paint film measurements. However, one can measure features of both the binding film and the $\mathrm{TiO}_{2}$ in something as dark as "battleship gray."

\section{Conclusions}

Our study to this point has identified some of the factors that may affect the Raman response of a complex sample. The physical properties of a sample affect the intensity of the Raman signal in complex ways. That this is so does not make it impossible to derive quantitative chemical information from complex samples. In dealing with specific samples it is nearly always possible to set specific boundaries to the physical properties and handle their effects on an ad hoc basis. One promising avenue that we intend to explore is the use of partial least squares methods to derive information on the physical properties of the sample from the Raman response.

\section{TABLE 20-1 Compounds Studied}

\begin{tabular}{|c|c|c|}
\hline Name & Formula & CAS\# \\
\hline azo yellow & & $61036-28-0$ \\
\hline barium sulfate & $\mathrm{BaSO}_{4}$ & $7727-43-7$ \\
\hline cobalt (II) chloride hexahydrate & $\mathrm{CoCl}_{2} \cdot 6 \mathrm{H}_{2} \mathrm{O}$ & $7791-13-1$ \\
\hline cobalt green & $\mathrm{CoO} \cdot \mathrm{ZnO}$ & \\
\hline sodium cesium nickel (II) ferrocyanide & $\mathrm{NaCsNiFe}(\mathrm{CN})_{6}$ & \\
\hline copper phthalocyanine & & $147-14-8$ \\
\hline iron (III) oxide & $\mathrm{Fe}_{2} \mathrm{O}_{3}$ & $1309-37-1$ \\
\hline potassium dichromate & $\mathrm{K}_{2} \mathrm{Cr}_{2} \mathrm{O}_{7}$ & $7778-50-9$ \\
\hline potassium ferricyanide & $\mathrm{K}_{3} \mathrm{Fe}(\mathrm{CN})_{6}$ & $13746-66-2$ \\
\hline potassium ferrocyanide trihydrate & $\mathrm{K}_{4} \mathrm{Fe}(\mathrm{CN})_{6} \cdot 3 \mathrm{H}_{2} \mathrm{O}$ & $14459-95-1$ \\
\hline potassium permanganate & $\mathrm{KMnO}_{4}$ & $7722-64-7$ \\
\hline manganese (II) sulfate monohydrate & $\mathrm{MnSO}_{4} \cdot \mathrm{H}_{2} \mathrm{O}$ & $10034-96-5$ \\
\hline sodium ferricyanide monohydrate & $\mathrm{Na}_{3} \mathrm{Fe}(\mathrm{CN})_{6} \cdot \mathrm{H}_{2} \mathrm{O}$ & \\
\hline sodium ferrocyanide decahydrate & $\mathrm{Na}_{4} \mathrm{Fe}(\mathrm{CN})_{6} \cdot 10 \mathrm{H}_{2} \mathrm{O}$ & $13601-19-9$ \\
\hline sodium nickel (II) ferrocyanide & $\mathrm{Na}_{2} \mathrm{NiFe}(\mathrm{CN})_{6}$ & \\
\hline nickel (II) ferrocyanide & $\mathrm{Ni}_{2} \mathrm{Fe}(\mathrm{CN})_{6}$ & $14874-78-3$ \\
\hline $\begin{array}{l}\text { nickel (II) hydroxide } \\
\text { nickel titanate yellow }\end{array}$ & $\mathrm{Ni}(\mathrm{OH})_{2}$ & $12054-48-7$ \\
\hline prussian blue & $\mathrm{Fe}_{4}\left[\mathrm{Fe}(\mathrm{CN})_{6}\right]_{3}$ & $14038-43-8$ \\
\hline 29H,31H-phthalocyanine & & $574-93-6$ \\
\hline $\begin{array}{l}\text { sandorin violet BL, carbazole dioxazine violet } \\
\text { wollastonite }\end{array}$ & & $6358-30-1$ \\
\hline
\end{tabular}


WHC-SD-TD-RPT-015 RIV 0

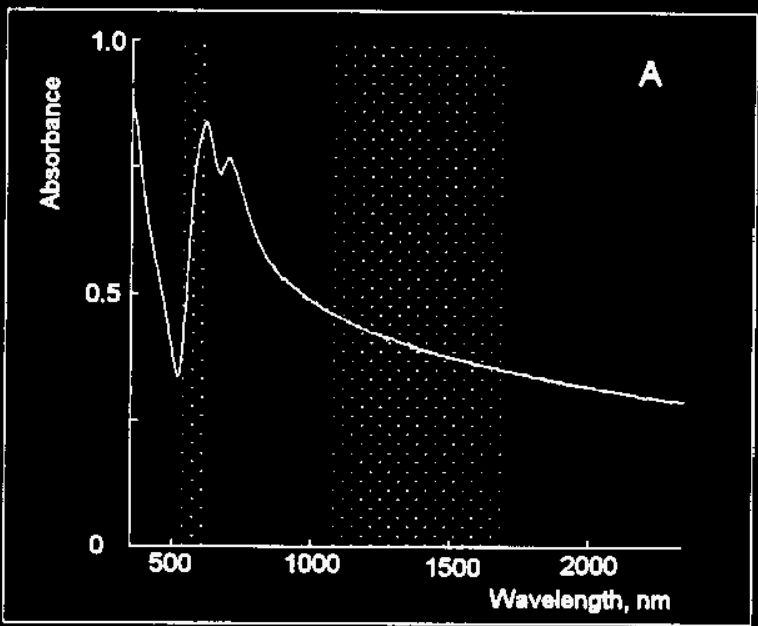

Figure 20-1


Figure 20-2

Effect of particle size

Diem. in micrometers 
WHC-SD-TD-RPT-015 REV 0

Figure 20-3. Effect of particle size

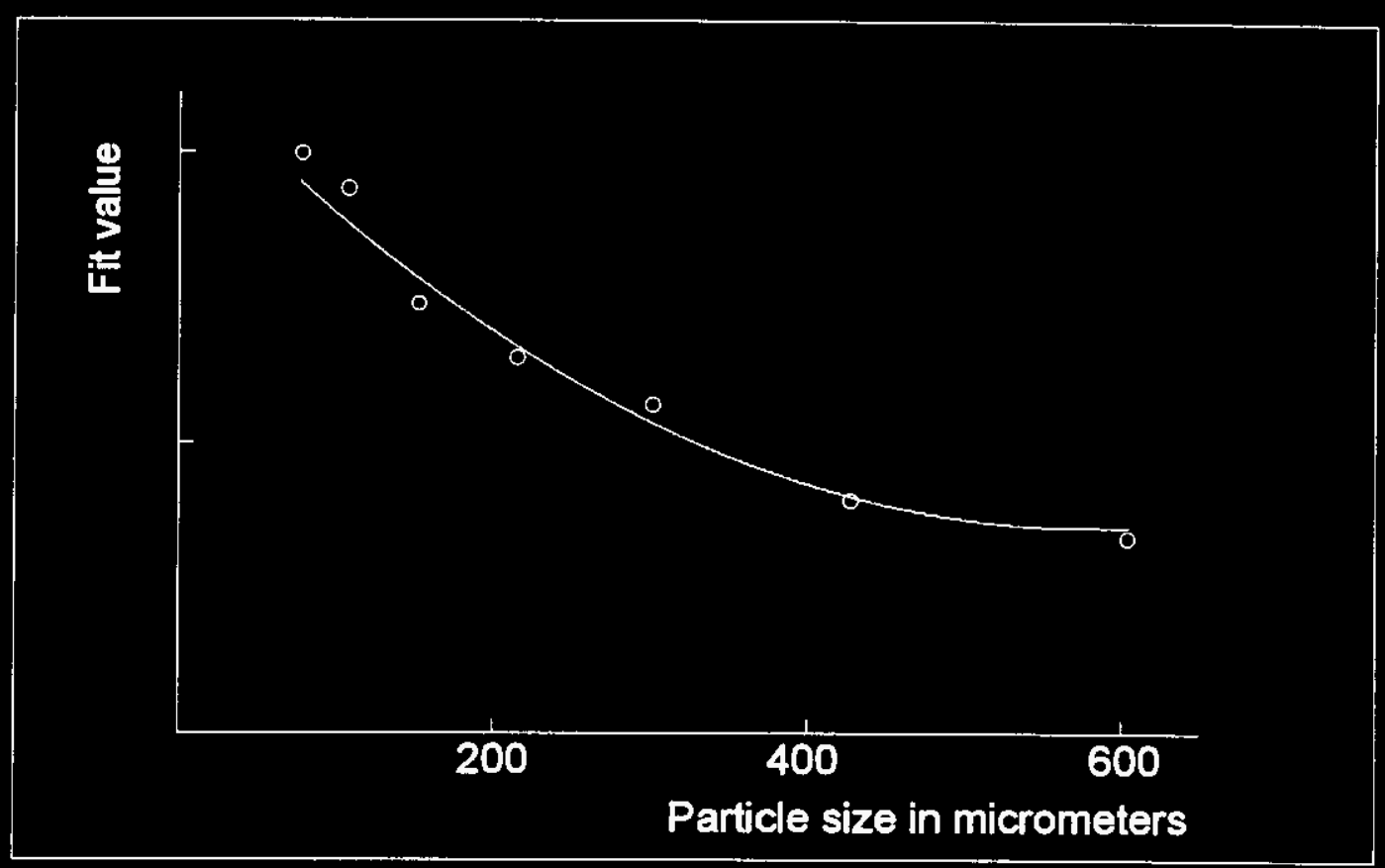




\section{WHC-SD-TD-RPT-015 REV 0}

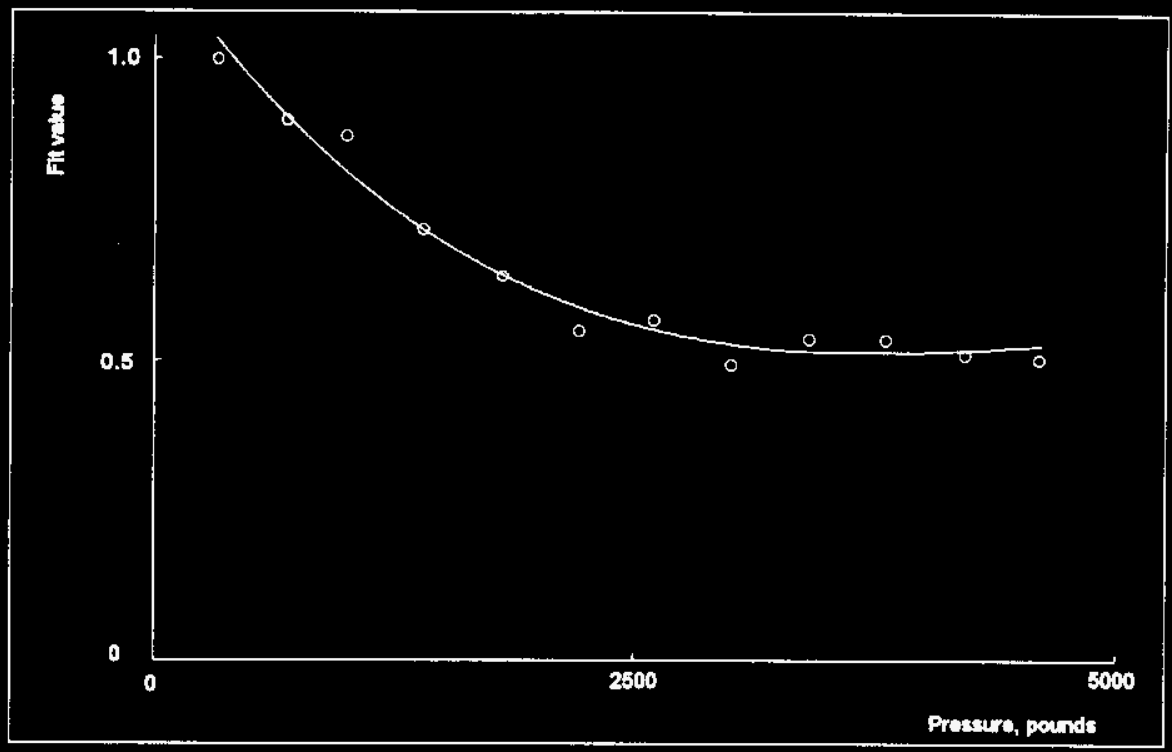

Figure 20-4

Pressure in pellet formation 


\section{WHC-SD-TD-RPT-015 REV 0}

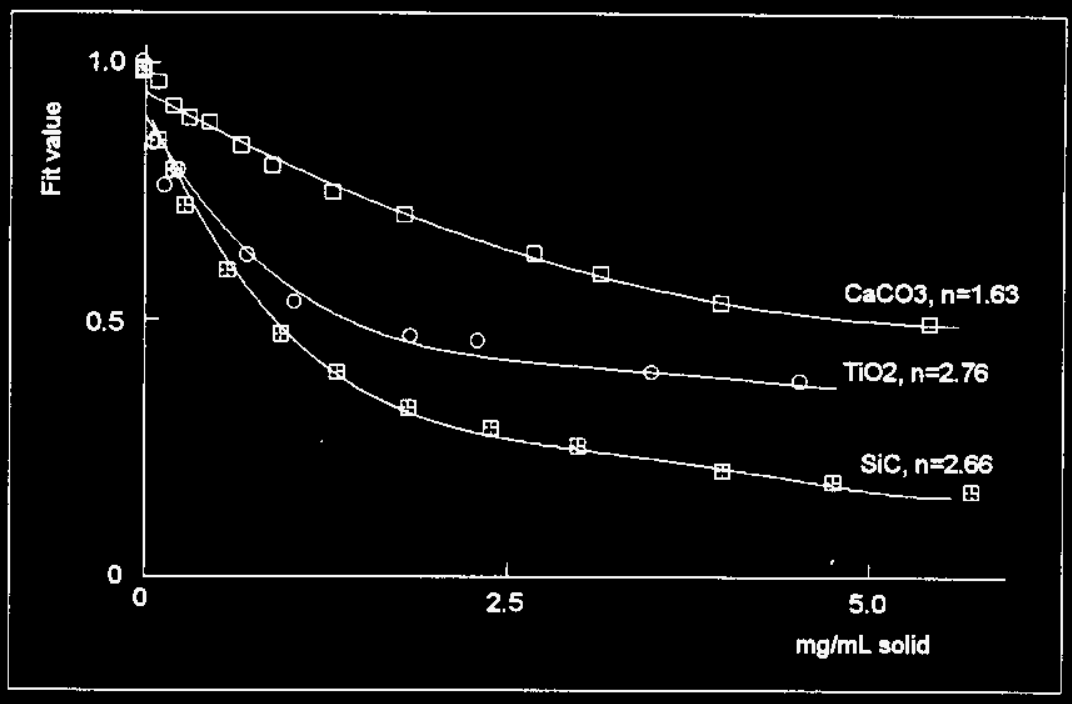

Figure 20-5

Suspended solids

Figure 20-6 Comparison of Color \& Refractive Index

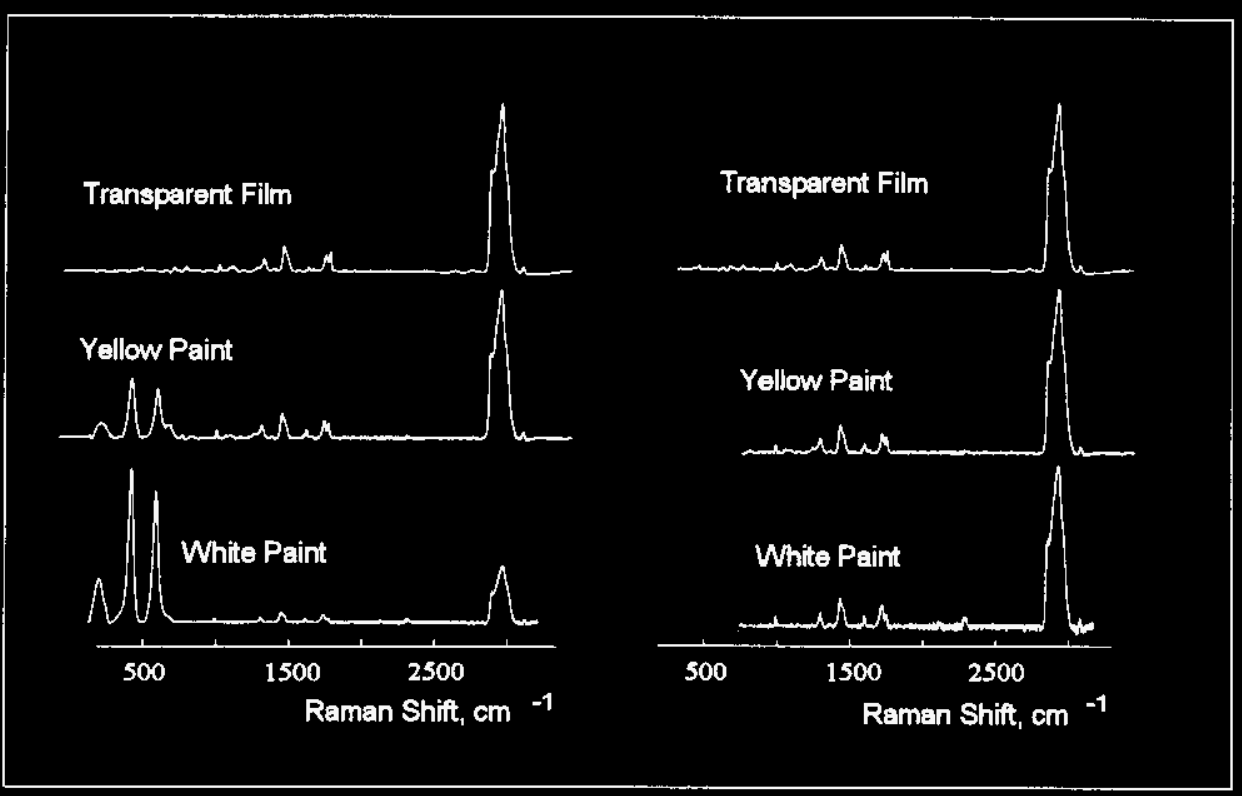


TASK 21: ANALYSIS OF UNKNOWN TANK MATERIALS SPECIES

\section{Introduction}

Conditions in the waste tanks may have led to the evolution of a variety of chemical products from the known inputs. The major thrust of this task has been the continued development of a library of reference spectra for use in identifying chemical species in the tank waste materials.

\section{Results}

Work in this area was intended to proceed in tandem with measurements on actual waste materials at Hanford. One material identified for investigation was prussian blue. The spectrum of this material is shown in Fig. 21-1. Spectra of a number of other species have been obtained as part of the work under task 20. These are shown in Appendix 20-1. 


\section{WHC-SD-TD-RPT-015 REV 0}



Figure 21-1 


\section{TASK 22: ALGORITHM FOR DETERMINING RELATIVE SPECIES CONCENTRATION}

\section{Introduction}

Although we have not completed the study of the effects of sample morphology on the Raman response of a sample, considerable use can be made from Raman measurements. It might be useful, for example, to be able to determine the amount of nitrite relative to the amount of nitrate in a particular core segment and to know how the relative amounts of each change with position in the core or from core to core.

The goals of Task 22 were to provide the tools needed for relative species concentration. The key development required for this task is the implementation of the ability to compare intensities of widely separated features in the Raman spectrum of a sample. The current system allows for correction of spectra for pixel-to-pixel variation within a detector window. It assumes the output of the white light source used for this purpose is constant with wavelength over the spectral width of a window. This is an approximation. It does not provide for comparison of intensities between windows.

The major goals of Task 22 were the development of a white light calibration procedure and the development of a chemical reference standard. White light calibration characterizes the spectrometer to allow accurate intensity comparisons over the full operating range of the Raman system. The chemical reference standard provides a test of total system performance, including performance of the laser and probe portion.

There are several components of the white light calibration process: (a) calibration of convenient laboratory standards, (b) application of the laboratory standards in providing Raman spectra corrected for instrumental factors, (c) providing a basis for comparing performance of systems, and (d) providing absolute intensity information.

\section{Calibration of a Working White Light Standard Source}

The working white light standard should be designed to be small, rugged, and easily replicated so that it can be incorporated into each Raman system for routine use. It is calibrated by comparing its output to that of a standard lamp that has a calibration traceable to a NIST standard. The working standard source is an assembly consisting of a miniature quartz halogen bulb, a flashed glass diffuser, and an optical fiber in a rigid mounting. The lamp is powered by a regulated $5-\mathrm{V}$ power supply.

The current FSU working lamp design is easily fabricated from readily available components. The shelf standard lamp has a known spectral radiance when operated at a specified current. The spectral radiance is given as $\mathrm{W} \mathrm{cm} \mathrm{cr}^{-1} \AA^{-1}$ for selected wavelengths over the range from 400 to $1100 \mathrm{~nm}$. W can be converted to photons $\mathrm{s}^{-1}$ and an equation derived to describe the spectral radiance versus wavelength for the shelf standard lamp. The standard lamp is mounted in a jig that allows it to illuminate an optical fiber in such a way that the geometry of the jig defines the area of the source and the solid 
angle collected. The distal end of the fiber thus becomes a source of known spectral radiance (photons $\mathrm{s}^{-1} \mathrm{~cm}^{-2} \mathrm{sr}^{-1} \AA^{-1}$ ). The simple design of this system provides a calibrated laboratory standards for field Raman instruments.

In principle any spectrometer sensitive to radiation in the appropriate wavelength range can be used for the source calibration. In practice it is convenient to use a laboratory Raman spectrometer for this purpose. The working standard source is calibrated by comparing the signal produced by it at a given detector element with the signal produced by the shelf standard at the same detector element when the comparison spectrometer is alternately illuminated by the shelf and working standard sources. The signal at detector element $i$ is given by

$$
S_{i}=\Phi_{i} Q_{i} t G
$$

where $\Phi_{\mathrm{i}}$ is the radiant power incident on element $i$ (photons $\mathrm{s}^{-1}$ ), $\mathrm{Q}_{\mathrm{i}}$ is the quantum efficiency (electrons photons ${ }^{-1}$ ) of element $i$ for the incident radiation, $t$ is the integration time, and $G$ is the gain of the amplifier and A/D converter combination.

The radiant power at an element is given by

$$
\Phi_{i}=B_{\lambda} \frac{w_{p}}{M} h \Omega_{e f} T_{0 i} D_{i} W,
$$

where $B_{\lambda}$ is the spectral radiance of the white light source. $w_{p}$ is the width of a detector element, $M$ is the image magnification produced by the external optics, so $w_{p} M$ is the width of a pixel projected on the fiber source. $h$ is the effective source height, the fiber diameter, which assumes that pixels are binned in the direction parallel to slit height. $\Omega_{\mathrm{ef}}$ is the solid angle of emission for the fiber, the limiting element in our optical train. $T_{0 \mathrm{i}}$ is the transmission efficiency of the optics, $D_{\mathrm{i}}$ is the reciprocal linear dispersion of the spectrograph and $W$ is the width of the entrance slit.

When working, $w$, and shelf, $s$, standard sources are compared at a single detector element, assuming identical fibers are used in coupling each to the spectrograph,

$$
B_{\lambda w}=\frac{S_{w i} t_{s}}{S_{s i} t_{w}} B_{\lambda s} .
$$

In calibrating a working standard source the spectra are measured for each source in alternation, adjusting the spectrometer to provide overlapping observation windows covering the range from 4000 to $10,000 \AA$. Readings at multiple pixel positions within each window are used in calculating the St ratio. The large number of independent observations provides a robust calibration transfer. Calibrabrations have been completed using this procedure and are currently being refined and tested for accuracy and reproducibility of the procedures. 


\section{Correcting Raman Spectra}

When the Raman measurements are made the measuring instrument is characterized by recording its response to a known source, the working white light standard source. Thisinformation is used to produce a correction set. Each point in a Raman spectrum is multiplied by the corresponding point in the correction set to produce the corrected Raman spectrum. The signal produced by the white light source is

$$
S_{w i}=B_{\lambda w} \frac{w_{p}}{M} h_{w} \Omega_{\alpha f w} T_{0 i} D_{i} W Q_{i} t_{w} G
$$

Similarly, the signal due to the Raman spectrum at any pixel is

$$
S_{R i}=B_{R} \frac{w_{p}}{M} h_{R} \Omega_{e R} T_{0 i} D_{i} W Q_{i} t_{R} G
$$

The corrected Raman intensity at a given pixel is

$$
B_{R}=\frac{B_{2 w}}{S_{w i}} \frac{h_{w} t_{w}}{h_{R} t_{R}} S_{R i}
$$

\section{Comparing Raman Systems}

The calibrated working white light standard can also be used as a basis for comparing the performance of Raman spectrometers. A useful figure-of-merit in characterizing a Raman spectrometer is the signal produced for a given exposure at a given resolution. Rearranging Eq. (4) as shown in Eq. (7) demonstrates that this quantity, to the left of the equals sign, depends on a number of spectrograph and detector properties. With the working standard it should be practical to compare this figure-of-merit versus wavelength for the various spectrometers proposed for use in this project.

$$
\frac{S_{w}}{B_{\lambda w} t_{w} W}=\frac{w_{p}}{M} h_{w} \Omega_{e f w} T_{0 i} D_{i} Q_{i} G
$$




\section{Absolute Intensity Measurements}

At this stage of the project the primary concern is in comparing spectra on a relative intensity scale, but the discussion above suggests that it is feasible to measure Raman spectra in a way that will provide absolute intensities.

\section{Chemical Reference Standard}

To test the performance of a complete Raman system, a chemically stable Raman scatterer is desired that can be reliably placed at the sample position of the probe. In remote measurements the system operator will not have ready access to the sample end of the probe. It is believed that solid polymeric materials are the best candidates for use as a chemical reference standard. A number of materials have been considered for this use and the provisional choice is CR-39. CR-39 is a high grade optical plastic widely used in the manufacture of eyeglass lenses. It is a highly cross-linked thermoset homopolymer prepared from diethyleneglycol bis(allyl carbonate). Chemical reference standards have been made for laboratory use containing a rod of CR-39 in a metal container with a fiber optic connector. This is being used to accumulate data on system reliability for FSU Raman instruments. It is proposed that FSU supply copies of this assembly for use at Hanford. The CR-39 has been sent to Kevin Kyle at Lawrence Livermore Laboratories for incorporation in the Raman unit currently under development for tank measurements. 


\section{Task 23: Core Screening}

\section{Introduction}

The purpose of this task is to develop software that will detect substantial differences in chemical composition of tank core materials, based on the use of repeated Raman measurements. This software examines two spectra which have been corrected for dark current and for wavelength-dependent system variations. In addition to the two sample spectra, probe spectra appropriate to each sample with dark and wavelength-dependent artifacts removed are required.

The algorithm produces an estimate of the Raman features for each spectrum with silica and broad wavelength interferences, such as sample fluorescence, minimized. In operation, the software can be configured to provide the operator with a binary decision regarding the similarity of the Raman spectra. It can also provide a display of the reduced Raman spectra. If desired, reduced spectra and a log of descriptive information can be retained as data files.

The software described in this report is designed to deal with the types of sets which have been obtained from Hanford. It is intended to be used with either 1024- or 1152point sets obtained from small single stage spectrographs, such as the J-Y $640 \mathrm{~mm}$ or Spex $250 \mathrm{~mm}$ instruments. Some refinements have been introduced as a result of tests with data that have been obtained at FSU. To meet the requirements of the task, all software components have been written as modules which can be called individually.

The specific implementation of these modules in a program will vary depending upon the purpose. At this time a program exists which provides dialog-box access to the various modules in a format that is useful to a user who is familiar with RCAL sofware. This user interface will have to be replaced with one that is appropriate for screening with technician operators. That can readily be done but it involves knowledge of specific details of the operation.

The software described is intended to be used with the instruments which have been in operation both at Hanford and at FSU. During the period in which this report has been written, a new type of spectrometer, the Kaiser Holoprobe, has been placed in service both at FSU. This instrument is sufficiently superior to what has been available to date that it seems likely to be widely used. Accordingly, there is reason to consider how to implement this concept with it, which is discussed towards the end of this report.

In addition, Kaiser Holospec instruments are in use at Hanford. Data from a Holospec is obtained in 1152 elements which cover approximately $2000 \mathrm{~cm}^{-1}$. With many spectra, the procedures described below will give satisfactory results. However, if the data are stretched to give a presentation which is linear in wavenumber, the segmented procedure that is described for the Holoprobe will be needed. It isn't possible to fit a single 
polynomial to a 2000-point Raman signal as a general purpose operation as there will be too many unsatisfactory cases.

\section{Real-Time Laboratory Viewer}

One of the other uses for this algorithm is that of a real-time spectrum viewer, suitable for routine laboratory use. Quite often the broad band components in a spectrum are strong enough to obscure Raman components. When this happens, one may not know whether there has been any useful result until the measurement session has been completed and there is opportunity to examine the data. The routines developed in this task require around five seconds to run on a $66 \mathrm{MHz} 486$. Accordingly they are restricted to use with exposure times of six seconds and longer.

This is fast enough to be useful since most measurements take that long but it would be better to reduce the run time. There are a variety of ways to do this: optimize the code, write time-consuming routines in assembly language, recast the program as a DOS application, nun the program on a faster computer. For the short run, the first option is most attractive. No specific thought has been made for the run time option. However, a significant improvement in performance is certainly possible. For the longer term, the last option, a faster computer system, appears to be the most cost-effective. A combination of faster hardware and 32-bit compilation to use with Windows95 will probably increase speed as much as is useful, without incurring any expense that would not otherwise be encountered.

\section{Off-Line Data Processing}

This software can also serve as a data processing tool to reduce the amount of hand work that is required to produce high quality spectra. In some cases, the completely automated sequence will give satisfactory results. More often, that will not be true. Accordingly, other options are offered. Operations that perform removal of silica and of other broadband components can be separated. The band passes of filters that are used in the computations can be adjusted.

\section{Overview of the Design}

The procedure involves subtraction of the silica probe spectrum, followed by removal of the broadband interferences such as fluorescence, heating and stray light contributions by a fitting procedure. 
Subtraction is the appropriate procedure for dealing with the probe spectral noise contributions because they can be determined in an independent measurement. In most
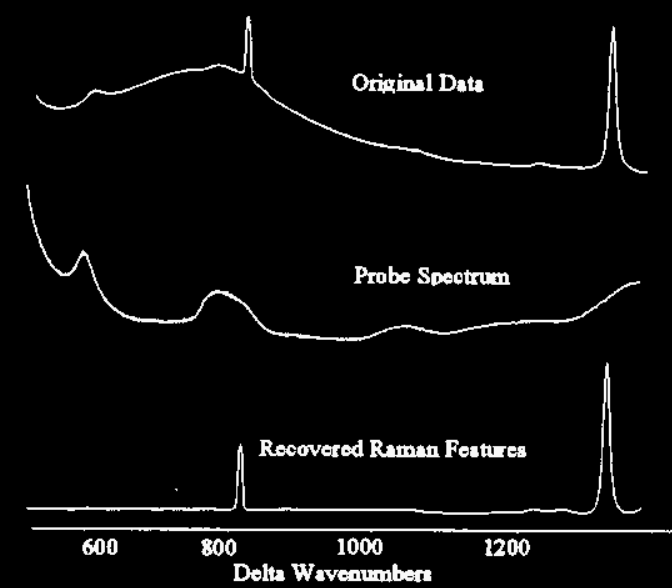

Figure 1 Example, start to finish. cases, the sample and probe components combine linearly and a subtraction achieves good results.

The broadband components are by definition not known. Moreover, they change from sample to sample, even when the operator is unaware of changing conditions. The handle that is available to deal with them is that their spectral changes are much slower, on a wavelength bases, than the changed from valid Raman spectral components. Accordingly, their influence can be minimized by fitting a spline. The major requirement is that the Raman features must be prevented from

contributing to the fitting process.

The complete procedure is illustrated in Fig. 1. The upper curve shows the original data (dark current and detector pixel pattern removed). The middle curve is the probe spectrum. The bottom curve is the result of subtracting the scaled probe spectrum and removing the estimated fluorescence component.

\section{Silica Removal}

This algorithm is based on the assumption that at least one silica feature is adequately free of interfering Raman peaks, either because they are absent or that they are too small, relative to the silica features, to cause trouble.

Evidently, this requirement is not always met. The design could be altered to estimate the shape of interfering Raman peaks. However, at the present it appears that the restriction is met in such a high fraction of cases in which an unfiltered probe is used that the increased run time associated with the refinement makes it not worthwhile. When the routines are used for final data processing, the operator can always substitute interactive subtraction for the first step of the calculation.

The silica removal algorithm has been designed to operate without prior knowledge of the position of silica bands. The algorithm scans the probe spectrum to find the bands, operating on the premise that this set contains only silica features.

The advantage of this approach is that it allows the software to be applied to spectra that have not been acquired by RCAL-compliant acquisition programs. The disadvantage is that run time is extended. The software would operate faster if the silica peaks positions were deduced based on wavelength data. 


\section{Seanning the Probe Spectrum}

The peak locator routine, described below, is used to determine where the main silica peaks are. $A$ probe spectrum may also have an additional background feature which can interfere with estimates of the relative sizes of silica features.

To avoid this, a copy of the probe spectrum is formed. From it the silica features are shaved by replacing them with a straight-line segment that connects the peak wings. This shaved set is subtracted from a copy of the probe spectrum to produce a set that has the silica features on a substantially flat background. The variances of each detected silica feature are compared with the total variance of the baseline-corrected set. Those having a variance of at least one tenth the total are accepted as valid silica features.

\section{Determining the Probe Spectrum Scaling Factor}

Having estimated the location of the major silica features, the next step is to determine the size of the probe contribution to the sample spectrum. This is accomplished by doing a simultaneous least-squares fit of the probe spectrum, a DC level and a ramp to the sample spectrum, with the scope of the fit calculation restricted to the range of the silica feature being tested. One output from each of these calculations is a quantitative estimate of the contribution of the probe to the sample, based on one silica feature. The combination of restricting the scope of the calculation to a limited spectral range and of using DC and ramp segments makes this calculation substantially immune to interference by the broadband components, fluorescence, heating effects and stray light effects, which should occur only in the sample spectrum.

The second piece of information obtained is a measure of the goodness of fit of the calculation. This is used to decide which the silica features is best suited to serve as the basis for removal of probe effects. Here the effect of the interference of sample Raman peaks on the silica removal procedure is assessed. In the existing software, the feature that produces the best fit is used.

However, at this point one could instead make a decision about the quality of the best fit. If the best fit showed unacceptable interference from sample Raman peaks, these could be discriminated against by taking advantage of the fact that silica features are significantly broader than those of most other Raman peaks. Such a procedure could efficiently discriminate against most Raman interference. However, it would have problems with peaks from amorphous polymers.

This capability has not been included because the gain in quality control is outweighed by the loss in computation time. When unfiltered probes are used, the silica features are very nearly always large enough to make the algorithm work well enough for real-time screening purposes.

\section{Removal of the Silica Contribution}

The procedure described identifies the best silica feature on which to base the subtraction and provides a quantitative measure of its contribution. 
The process is completed by using the scale factor to subtract the original probe spectrum from a copy of the original sample spectrum. For this step the DC and ramp responses are not used. The result is an estimate of the spectrum with silica removed but with other broadband interferences still present.

\section{Spectra Made With Filtered Probes}

In operation with filtered probes which have the filter is at the probe tip, no silica removal routine should be needed.

\section{Peak Location}

At various stages of the whole process it is necessary to locate the positions and intensities of peaks in a spectrum. Accordingly, a general-purpose peak locator has been written.

\section{Minimizing Background Effects}

Before attempting to locate peaks, the major components in the background that are wider than Raman peaks are removed. This is done by fitting a spline to the whole set. The default is a 6th order spline of the same length as the set. This is subtracted from a copy of the original data to form a preliminary estimate of the baselime-corrected set. The purpose is to locate peaks, so some procedure is required to deal with high frequency noise that will degrade peak recognition routines. Accordingly, the copy of the data set is smoothed by fitting a 4th order spline with 34 segments along the length of the data array.

\section{Filtering By Tiled Splines}

A tiled spline is produced by repeatedly fitting a polynomial to small segments of a set. The splimes are joined together to form the smoothed version of the original data. Because the segments are small, the polynomial can be stiff without distorting the underlying Raman features. The effect is of a filter with a very sharp cutoff.

The estimated baseline is subtracted from the smoothed set, causing the major peaks to appear superimposed on a reasonably straight and level baseline, which is generally somewhat negative because of the contribution that the peaks made during formation of the single spline.

Peak maxima are identified, after which the locations of the wings are picked out. Local maxima with intensities that exceed half the total standard deviation of the baselinecorrected set are accepted as significant Raman peaks. The location of a peak wing in a set which has much Lorentzian character is bound to be arbitrary. Here a wing is taken as the point nearest the peak maximum at which the slope has dropped below 1 and the intensity is less than 0.1 of the total standard deviation of the set.

When peak wings are identified, the routine can detect the presence of superimposed peaks by noting the cases in which the maxima of adjacent peaks fall within the bounds of a neighboring one. If the peaks are small relative to the length of the set (less than one tenth of the length) the feature is taken to be a peak with a shoulder and the complex is 
reported as a single peak. If one of the peaks is too wide to pass the test, the incorporated peak is taken to be a narrow peak superimposed on a broad feature and it is reported as an independent narrow peak. This allows the details of valid Raman complexes to be retained while allowing the removal of broad background features which are unlikely to be valid Raman features.

\section{Data Logging}

Results from the peak locator routine are returned to the calling routine in a data array which is not seen externally. However, there is a function included which can save these results in a file on the hard disk. This is an ASCII table, one line for each peak, giving the positions in terms of data point index for the wings and maximum and the intensities for each of these points.

\section{Removal of Broadband Interferences}

Once the silica features have been removed, the remaining broadband features must be estimated and removed. The rationale for this operation is that the major broadband interferences (fluorescence, heating effects and instrument artifacts such as stray light contributions) are significantly wider than valid Raman peaks. Therefore one can identify and remove the Raman peaks to allow an estimate to be made of the broad features. The final product is obtained by subtracting this background estimate from the silica-corrected set.

If the default conditions for the calculations are accepted, this routine may remove the contributions of amorphous polymeric materials. The most common of these is the 1640$\mathrm{cm}^{-1}$ peak of water. Water peaks could be retained using a procedure that is conceptually similar to the silica removal routine, but that is not incorporated into the present software.

\section{Peak Shaving}

The background estimation is completed by fitting a single spline to the whole set. The default for this is a 6 th order spline. If an estimate is made by fitting the spline to the silicacorrected data set, the background will be seriously in error because of the influence of the Raman peaks on the fitting calculation. The estimated background will be too high in the regions where there are Raman peaks. Accordingly, they are removed before the background estimate is made.

The first step in this process is to locate the Raman peaks using the silica-corrected set as input to the peak locator routine described above.

On the basis of this information, the peaks that are located are shaved by replacing them with straight-line from left to right wing. This can give erroneous results when a weak peak is adjacent to a strong one. The small peak may not pass the intensity test in the peak locator routine. Accordingly the output from the preliminary pass is used as input to the peak locator routine in a second pass. The results from the two passes are combined and a no-peaks version of the data set is produced by replacing all detected peaks by linear segments. 


\section{Background Estimation}

Owing to the difficulty in locating the wings of peaks in vibrational spectra, the result of the peak shaving routine can have artifacts at the points corresponding to peak limits. Accordingly, the shaved set is smoothed in a two-pass tiled spline calculation which is designed to assure that the tiles overlap. This two-pass procedure guards against handling the case in which the edge of a tile happens to coincide with the edge of a shaved peak. Owing to the sharp cutoff behavior of tiled splines, the process can be repeated without significantly distorting the underlying low frequency information.

From the output of this operation, an estimated background is formed by fitting a single spline to the whole set. The default for this is a sixth order spline. This estimated background is subtracted from the silica corrected set to produce the estimate of the broadband-corrected Raman spectrum.

\section{Characteristics of the Corrected Spectrum}

The background estimation forces an overall flat background. This is reasonable because Raman spectra, unlike infrared, do not exhibit broadband underlying components. One can verify this by looking at collections of infrared and Raman spectra for the same components. This will also severely attenuate any valid Raman peak that does not survive the half standard deviation test in the second pass through peak locator routine. Expressed another way, a peak that has a $\mathbf{S} / \mathrm{N}<2$ is likely to be removed.

This is a two-step process that culminates in subtraction of the scaled probe spectrum from the original data. Here, what is meant by "original data", is the data from which the detector pattem and wavelength dependence have been removed. Although there are many smoothing operations involved in estimating the scale factor that is applied to the probe spectrum, the silica-corrected spectrum is not directly affected by any of them. It is just a scale and subtract operation at the final step.

In the second stage, an estimated background set is calculated which is smoothed. However, it is subtracted from the silica-corrected set. Accordingly, the final product contains all of the high frequency noise that was present in the original data.

\section{Screening Function}

This software was developed with the idea that it would be useful in three types of applications, routine real-time core screening, real-time preliminary data processing, and off-line detailed data processing. The version that is currently available actually is configured for the last case. However, all of the major components that are needed for both of the routine applications are incorporated. To implement these other applications, it is only necessary to specify the detailed context in which the software is to be used.

\section{Detector Driver Software}

A routine to control the spectrometer detector must still be developed or obtained from the detector manufacturer. The supplier of FSU's Raman detectors, Princeton Instruments (PI), no longer supports DOS applications and has not initiated full support of Windows based software applications. However, PI does have a program, WINVIEW, 
which is well suited for instrument setup. It readily produces an image which shows the lighting conditions on the detector chip. It will produce spectra, but is too awkward for any sort of routine Raman application because it is intended for imaging. PI is producing software for Original Equipment Manufacturing (OEM) applications. However, the first software priority for PI is the imaging applications. During the period of this work, they have just begun to supply DLL windows software that can be used with FSU's Raman detectors. There is no doubt that CCD detector chip control software for spectroscopy applications which requires binning will be forthcoming.

When detector control routines are available, it will be a relatively simple task to incorporate this software into a routine application. The program has been written and the software parts which are not dependent upon data acquisition have been debugged.

\section{Core Screening Decision Software}

The core screening decision software is designed to furnish two outputs to the operator. One is a display of the output of the two-stage background-correction routines that are described above while the second output (binary output) gives an estimate of whether the current spectrum set is or is not significantly different from its predecessor set.

The similarity decision will be generated by comparing the outputs of the peak locator routine. As described above, this is a tabulation of peak positions, intensities and widths. For this purpose, it will be obtained by passing the final product of the two-stage background correction to the peak locator routine. At each data acquisition, this will generate a small ASCI file which can be read as needed. The basic operation is simply a comparison of two tables to determine if the same peaks are present in both observations. There will have to be a weighting process to allow for uncertainty caused by experimental error. This is the type of application for which fuzzy logic is well suited. However, in order to produce and test this software that will do what is needed, it will be necessary to have access to spectra that are representative of those which will be met in practice.

\section{Use With the Kaiser Holoprobe Spectrometer}

The Kaiser Holoprobe spectrometer instrument produces data with a spectral window of approximately $4000 \mathrm{~cm}^{-1}$, with data points that are linear in wavenumber. The backgrounds are almost always too complex to be fit by a single polynomial. Therefore set must be split into sections which are processed and recombined at the end.

The software that is delivered with the instrument filters the data before the user has access to it. This sometimes interferes with the algorithms that have been developed here. They use the high spatial frequency noise that is always produced by a spectral detector in making the distinction between valid peaks and shoulders and the artifacts that are produced by chance combinations of noise components. It is not known if the filtering operation can be omitted in using this system with the manufacturers software. It will probably be necessary to develop custom data acquisition software for this instrument in order to be able to tailor its operation to meet needs with Hanford tank waste materials.

At this time, the fitting tools do work if the operator overrides decisions that are made by the automated routines. However, it is necessary to try an operation and then look at 
the results and assess their value. Sometimes it is necessary to change conditions, such as the order of spline used or to select a different size window on which to do the calculation. In the illustration below, the data set in Fig. 23-2 (produced by the Kaiser software) was subdivided into sections as indicated by the dashed boxes. Each segment was treated and the results were recombined to form Fig. 23-3.

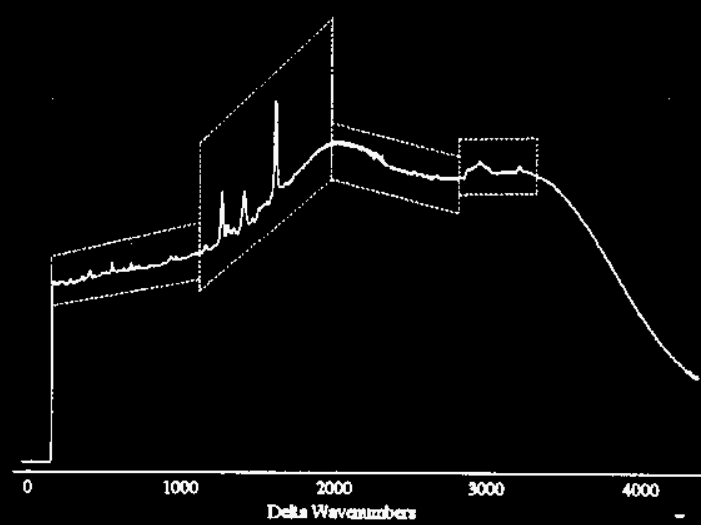

Figure 23-2 Original data. Boxes indicate zones for data processing to remove background.

Normally a manual process has been used to process Raman spectra. The use of this process has aided in the understanding how the process could be automated. First, the strong peaks in the entire spectrum would be located using the procedures described above. These peaks would be shaved off leaving a set with numerous flat sections and various sharp comers. This would be cut into segments, each around 1000 data points long, and a preliminary background estimated for each by fitting a spline, probably sixth order.

The estimated backgrounds would then be recombined to form an estimate of the background of the whole set. This will often not be a very satisfactory estimate, but it will indicate the general shape of the actual background. Its function is to serve as a basis for breaking the original set into segments to allow more accurate estimations to be made. The two-step process is necessary because it is rarely possible get a satisfactory fit of a spline to more than about 1000 points of a Raman spectrum. Problems arise if there is more than one major slope change in the segments.

The next step is to subdivide the sets into segments. In each segment, the major peaks are shaved and an estimate of the background made. The calculated background is then subtracted. The result is then scanned to determine if there are significant negative regions. The major problem encountered in background removal is that if the calculated background is too "high," the final result will have negative regions. This will occur only infrequently in the calculation that is described just above. But when it does, it will be necessary to isolate that region for special treatment. The problem will have occurred because the peak-shaving routine did not do a satisfactory job. When such cases are 
examined, the source of the problem is usually immediately obvious. The special treatment will be designed either to turn the job back to the operator for that section or to attempt to duplicate the manual repair that an operator would use.



Figure 23-3 Data of Fig. 23-2 with background removed manually.

\section{Linear in Wavenumber: Software Redesign}

Disperse instruments are inherently linear in wavelength and FT instruments linear in wavenumber. The Kaiser Holospec spectrometer system software produces output for the user that is linear in wavenumber. This is done by stretching the data set and selecting points that give the desired intervals. This procedure has been previously used and a paper published about the process in $1989 .{ }^{6}$

There are some aspects of the Kaiser Holospec system software which are not totally desirable. In particular, the user is not allowed to have access to the original data. This is not just a simple matter of unwanted filtering. In this software the data are extensively massaged before presentation to the user and all except the final version are deleted. The validity of data produced by this software is being tested by comparing its results with those obtained by interpolation with $\mathrm{Ne}$ lines. There are some inconsistencies which still remain to be resolved.

In this process, the convenience of a presentation that gives one wavenumber/data point is impressive. Unfortunately, with the Kaiser Holospec software, it is not arranged to be one even wavenumber. However, there does not seem to be any reason why the system could not be modified to produce this one data point per pixel conversion factor.

Accordingly, FSU is developing software that would give a presentation of one wavenumber/data point, with the abscissa selected to produce even wavenumbers (within the accuracy of the measurement) at each data point. This software would be suitable for any dispersive spectrometer. The original data sets will be retained as is done with the current RCAL software. It will be possible to have single-step conversion routines for any previously acquired data which was adequately sampled. 


\section{References}

1. D. R. Lombardi, C. Wang, B. Sun, A. W. Fountain II, T. J. Vickers, C. K. Mann, F. R. Reich, J. G. Douglas, B. A. Crawford and F. L. Kohlasch, Appl. Spectrosc. 48, 875 (1994).

2. T. N. Day, P. J. Hendra, A. J. Rest and A. J. Rowlands, Spectrochim. Acta 47A, 1251 (1991).

3. B. Schrader, A. Hoffmann and S. Keller, Spectrochim. Acta 47A, 1135 (1991).

4. J. D. Womack, C. K. Mann and T. J. Vickers, Appl. Spectrosc. 43, 527 (1989).

5. N. S. Guyot-Sionnest and V. A. Maroni, Appl. Spectrosc. 47, 556 (1993).

6. C.K. Mann and T.J. Vickers, "The use of Fourier Deconvolution to Correct for Instrument Slit Function Differences in Measured Spectra," Applied Spectroscopy 43, 3337 (1989). 

THIS PAGE NNTENTONALLY
LEFT BLANK 


\section{APPENDIX 20-1}

Comparison of visible and near infrared absorption spectra and Raman shift spectra obtained with $514.5 \mathrm{~nm}$ laser CCD system and with $1064 \mathrm{~nm}$ laser FT system

This appendix contains specific absorption and Raman spectra obtained for the materials listed previously in Table 20-1, in section 20-1 above. The absorption spectra below are displayed as absorbance $x 1000$ versus pixel number. The abscissa can be converted to wavelength in $\mathrm{nm}$ by assuming an origin at $350 \mathrm{~nm}$ and an increment of $2 \mathrm{~nm}$ per pixel.

The Raman spectra were obtained with $514.5 \mathrm{~nm}$ excitation and CCD detection are displayed as Raman intensity in arbitrary units versus wavenumber shift. The FT-Raman spectra obtained with $1064 \mathrm{~nm}$ excitation are displayed as arbitrary intensity versus pixel number. The abscissa can be converted to wavenumber shift by assuming an origin at a wavenumber shift value of $116 \mathrm{~cm}^{-1}$ with an increment of $1.28 \mathrm{~cm}^{-1}$ per pixel. 
THIS PAGE INTENMONAITY LEFT BLANK 
WHV-SD-TD-RPT-015 RUV 0

Absorption Spectra 
THIS PAGE INTENTIONALUY LEFT BLANK 

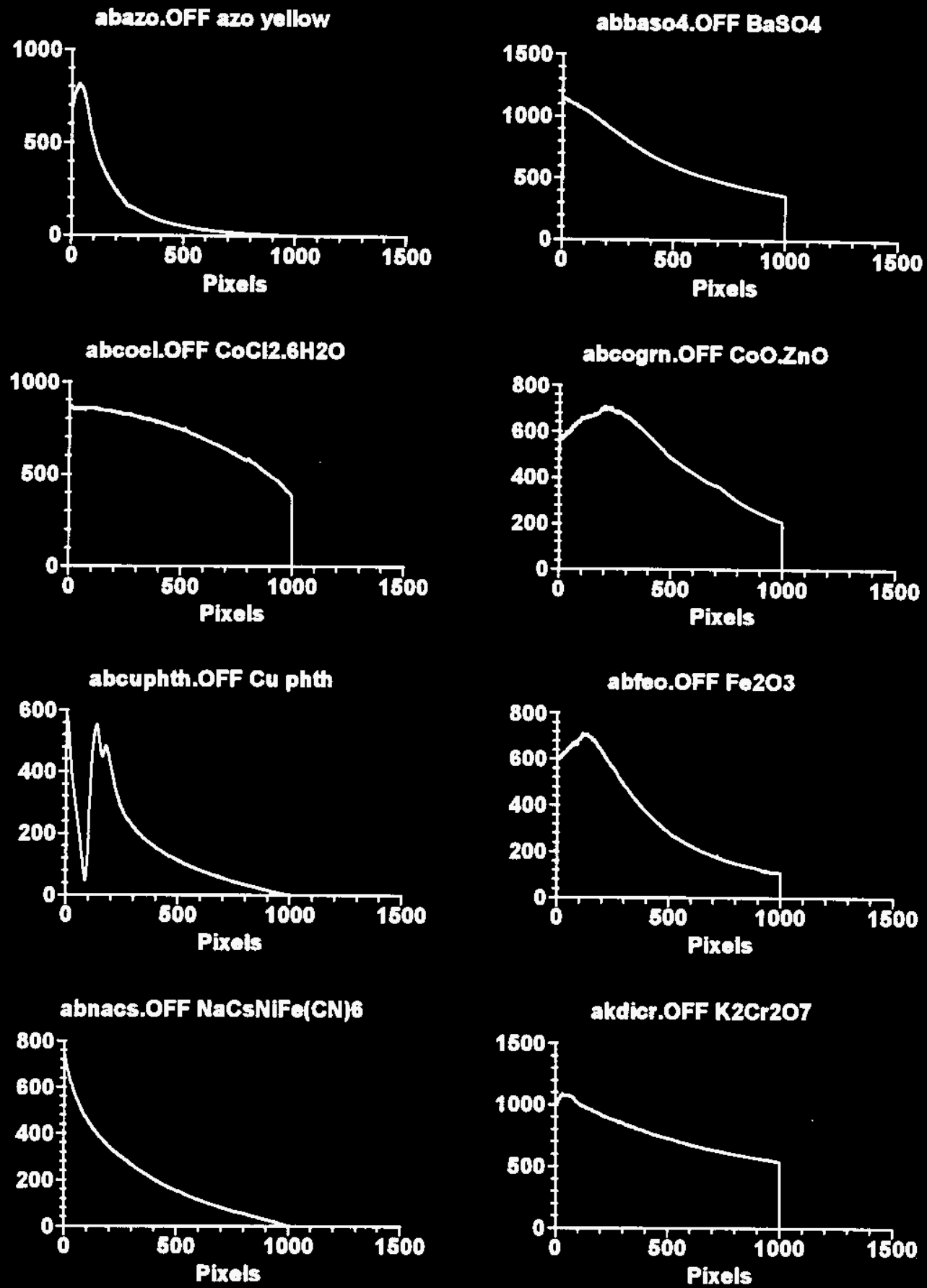

Pare 24898328 

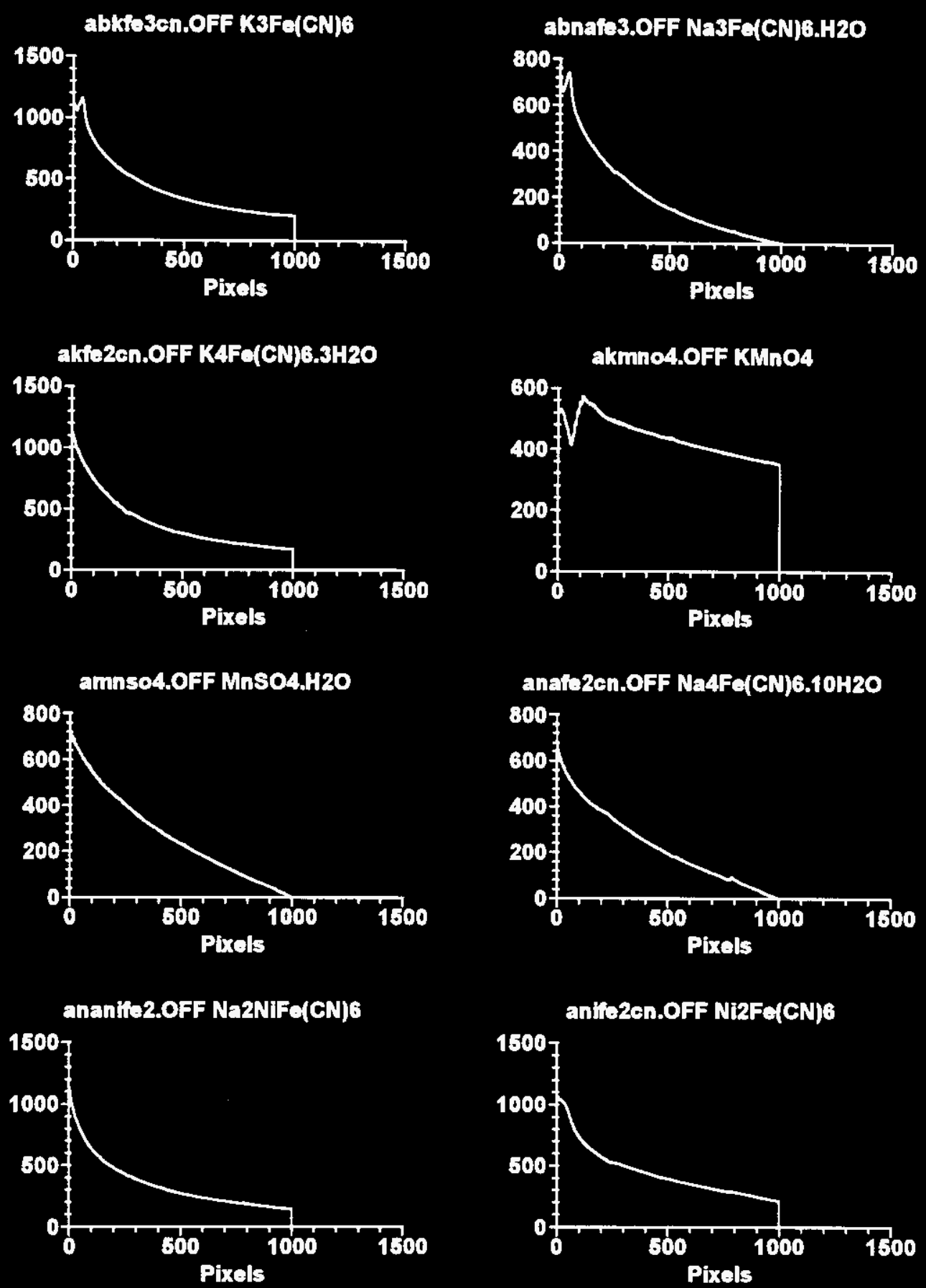

Paye 298a8d6 


THIS PAGE INIENTIONALLY LEFT BLANK 
WHC-SD-TD-RPT-015 REV 0

CCD Spectra 
THIS PAGE INTENTIONALIY LEFT BLANK 

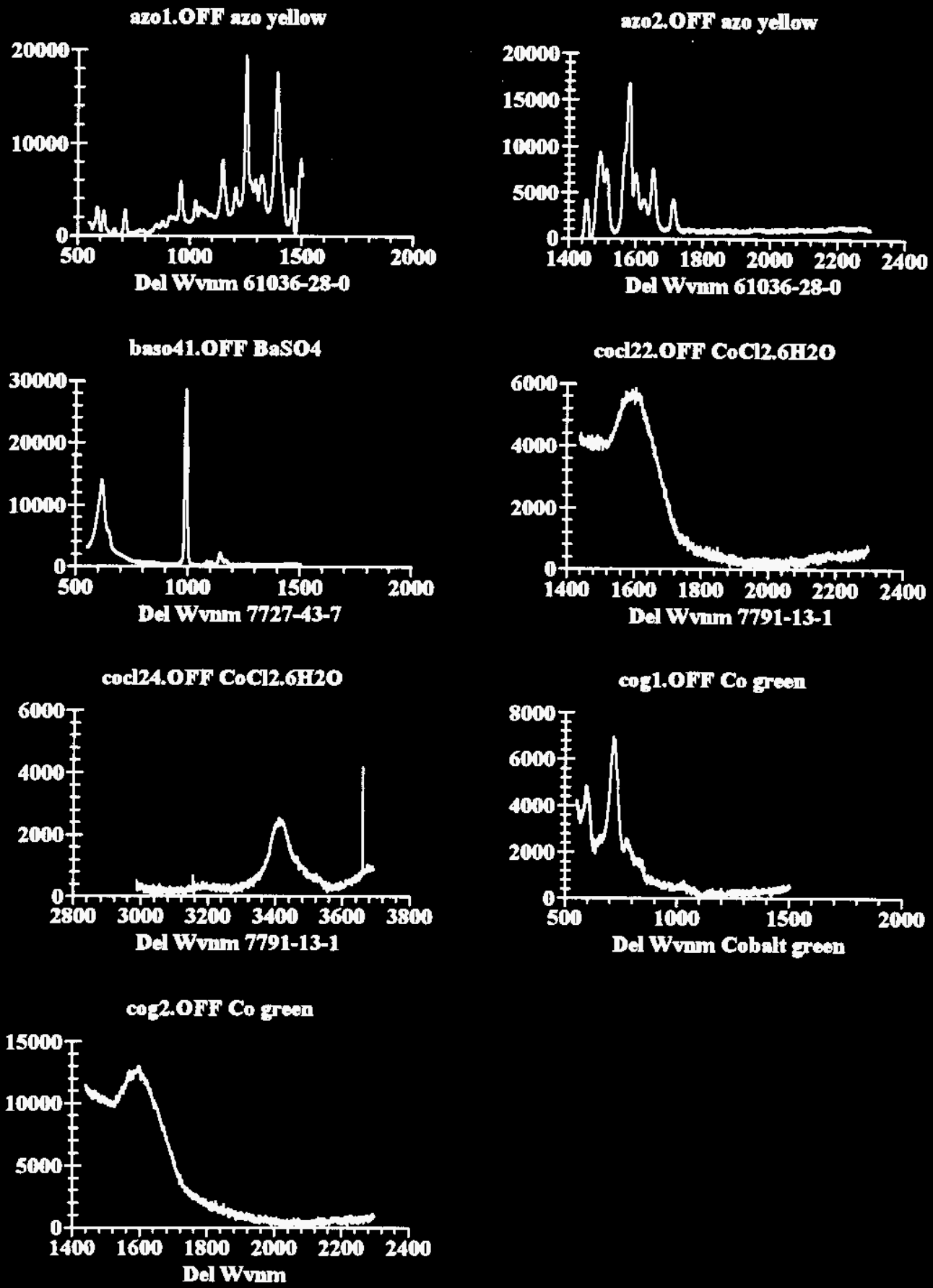

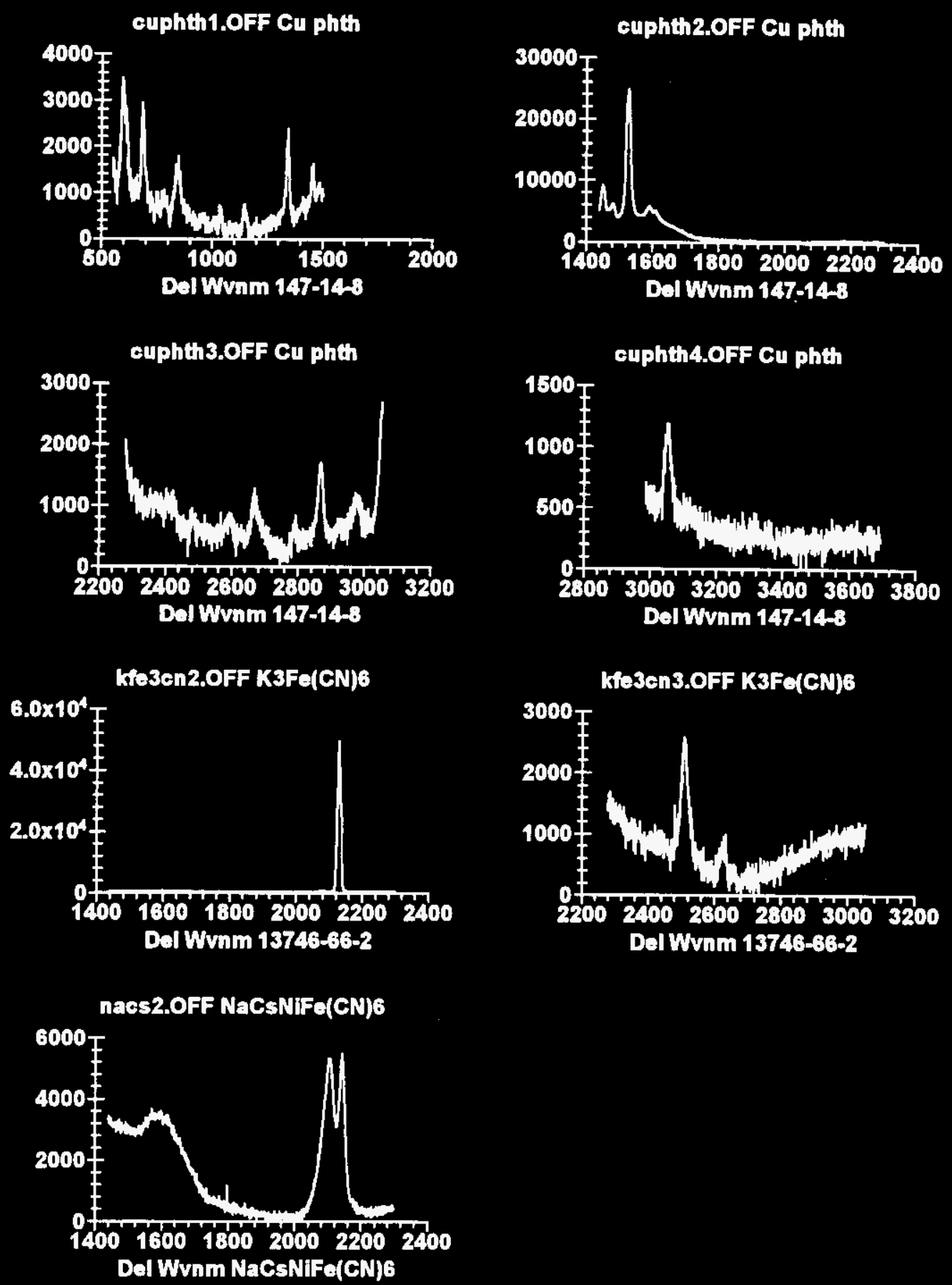

Pare 24a8b6e 

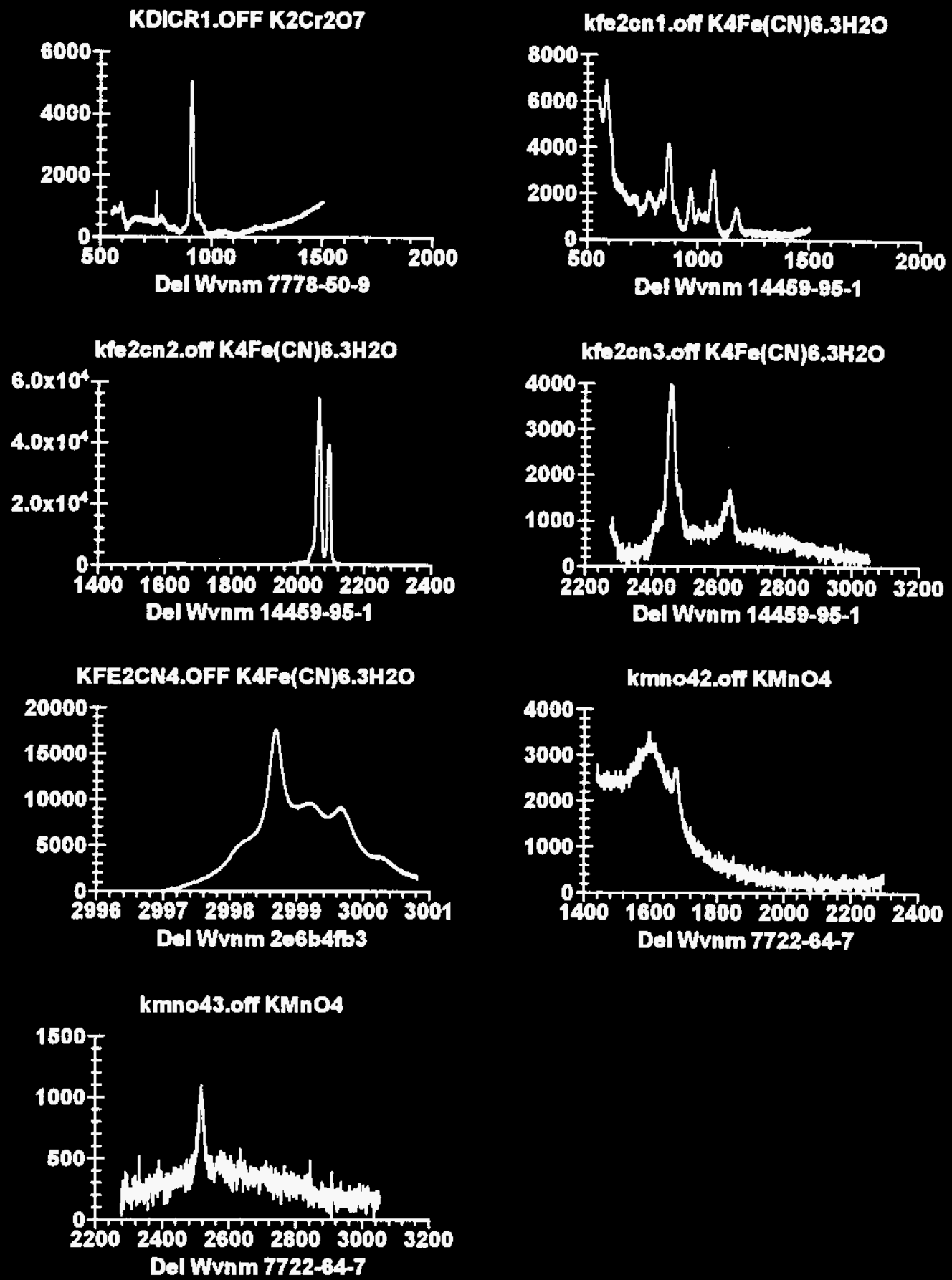

Pare 206b5490 



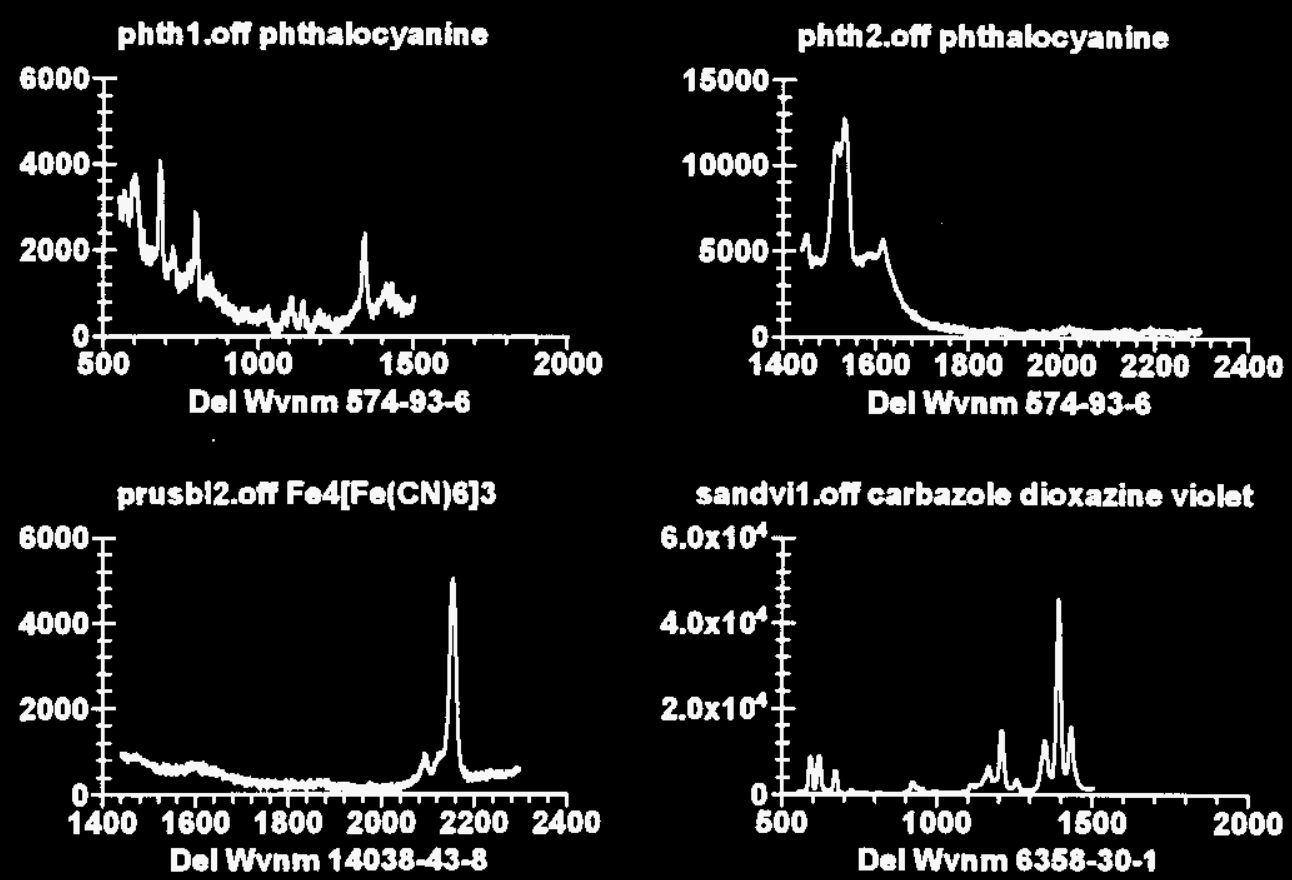

sandvi1.off earbazole dioxazine violet



sandv12.ofl carbazole dioxazine violat

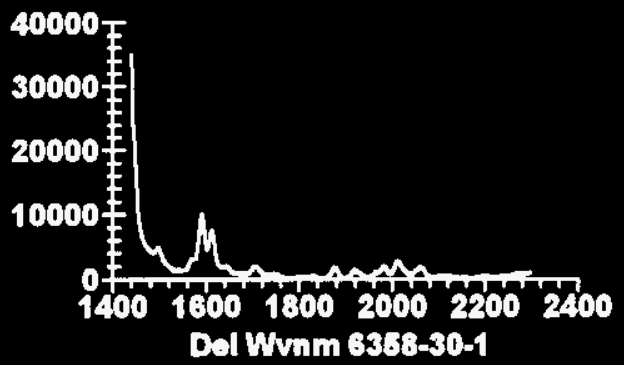

sandvi3.off carbazole dioxazine violet 40000

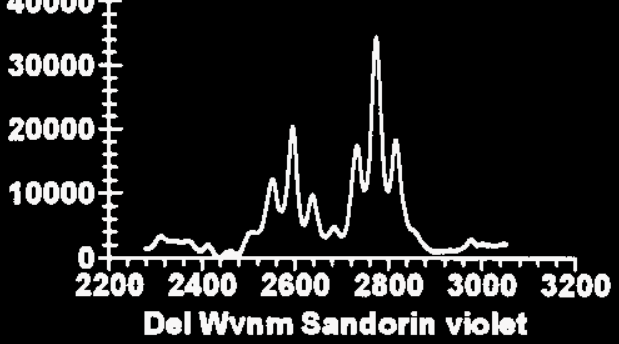


WHC-SD-TD-RPT-015 REV 0

Fourier Transform Spectra 



Pare 2e6b873b 
THIS PAGE INTANTONAWKY

IFHT BLANK 